MAFALDA SOARES DA CUNHA

ESTRATÉGIAS DE DISTINÇÃO E PODER SOCIAL: A CASA DE BRAGANÇA (1496-1640) 


\section{ESTRATÉGIAS DE DISTINÇÃO E PODER SOCIAL A Casa de Bragança (1496-1640) $\left({ }^{1}\right)$}

Se perspectivarmos a Casa de Bragança como um lugar institucional de promoção ou consolidação de poder podemos admitir que para além da existência de dispositivos formais e de práticas informais inerentes às próprias lógicas de organização do poder, e em particular do poder senhorial, houvesse também um conjunto de estratégias conscientes que direccionavam as acções da Casa, em particular no que respeita à promoção e à defesa da sua preeminência social. Será, pois, este o objectivo do sumário inquérito que aqui se ensaiará às estratégias de distinção adoptadas pelos duques de Bragança desde o seu retorno a Portugal, nos finais do século XV, até à subida ao trono em 1640.

A trajectória histórica dos Bragança revela metas e comportamentos diversos entre os séculos XV e os XVI e XVII. Enquanto a fase quatrocentista foi essencialmente dirigida à acumulação de recursos e de poder através do aproveitamento, ou até mesmo da criação, de conjunturas geradoras dessas mesmas

* Universidade de Évora.

(1) Este texto trata um pouco mais aprofundadamente alguns tópicos apresentados na "Introdução" da dissertação de doutoramento Redes Clientelares da Casa de Bragança (1560-1640), Universidade de Évora, 1997. 
possibilidades, o período subsequente parece ter sobretudo visado a consolidação e manutenção das posições sociais e políticas entretanto adquiridas. A alteração do contexto histórico e dos equilíbrios internos do reino parece não ter deixado aos Bragança margem para outro tipo de comportamentos, malgrado as opiniões de alguns dos seus cronistas.

O século XV fora um século marcado por lutas pela composição e recomposição dos poderes, em que os diferentes actores sociais parecem ter procurado estender as fronteiras da sua acção até atingirem limites virtualmente impossíveis de serem articulados com as áreas de intervenção do centro político. Os instrumentos de ordenação do espaço social que a Coroa criou e as necessidades de legitimação do seu próprio poder, decorrentes da implantação de uma nova linha dinástica, só tiveram os efeitos pretendidos a médio prazo. A titulação e as regras de precedências como instrumento de organização do topo do grupo nobiliárquico, o registo sistemático dos moradores da Casa Real como uma das formas de estruturação e ordenamento do espaço curial, a compilação e sistematização dos instrumentos legais e de intervenção jurídica concretizadas nas Ordenações Afonsinas e, finalmente, as múltiplas oportunidades (económicas e sociais) resultantes do alargamento do espaço territorial teriam continuidade e impacto definitivo sobre os três séculos subsequentes. Se lhes acrescentarmos as novidades administrativas criadas por D. Manuel - Reforma dos Forais, Regimentos dos ofícios, dos pesos e medidas, entre outros - poucas outras com tão significativas consequências ocorreriam antes do século XVIII.

Mas, como se disse, este fluxo de dispositivos de ordenamento do espaço político e social contrastava com o carácter ainda difuso e fluido do poder monárquico. A incorporação e a assimilação desses novos instrumentos de organização da sociedade foram lentas, permitindo que ainda coexistissem com as formas tradicionais de conquista e disputa do poder nas periferias. Ou seja, antes de conseguirem impor uma determinada ordem, suscitaram resistências e oposições por parte dos diversos organismos da sociedade. O que, de alguma forma, explica o desencadeamento de confrontos políticos internos com expressão militar ainda impregnados de sabor e formatos medievais e tornou possível o afã brigantino na acumulação de títulos, jurisdições, rendas, direitos, privilégios e alianças inter-nobiliárquicas ao longo da centúria de quatrocentos.

No século XVI, os novos recursos distributivos de que a Coroa 
passou a usufruir com a administração e a exploração comercial das áreas coloniais permitiram uma maior harmonização entre os esforços de intervenção política do centro sobre o território e o espaço social do reino. A monarquia distanciou-se definitivamente de todos os seus potenciais concorrentes internos, deixando, assim, de recear quaisquer excessos de acumulação de poder. Podia mesmo permitir que alguns pólos políticos se reforçassem e consolidassem. E era esta liberdade de actuação conferida àqueles que tinham sido tomados como os seus mais directos concorrentes que melhor evidenciava a diferenciação dos espaços de intervenção e a disparidade de recursos já existente entre a Coroa e os "corpos intermédios".

Neste novo contexto político, a Casa de Bragança direccionou a sua acção sobretudo para consolidar e reforçar as posições já adquiridas. Social e simbolicamente era difícil obter maior distinção que a de ser jurado herdeiro do trono, como ocorrera ao duque D. Jaime, logo no início do século XVI. A manutenção e a continuidade da indiscutivel preeminência assim reconhecida pela própria monarquia parece ter sido, pois, o principal objectivo que posteriormente orientou as acções da Casa Ducal. Foi, pelo menos, essa a convicção que, após 1640 e sob formas diferenciadas, se procurou criar e que terá contaminado alguma historiografia posterior. D. Francisco Manuel de Melo atribuía expressamente essa intenção a D. Teodósio II: "quando os seus íntimos o acusavam respeitosamente das conveniências que perdia [em não requerer ao soberano a herança de certos bens da Coroa pertencentes ao seu falecido irmão D. Filipe], costumava responder que aos seus antepassados coubera o papel de juntar e acrescentar à grandeza de sua casa, e à sua pessoa, por agora só competia trabalhar no sentido de manter o que em honra e fortuna, eles tinham ganho" $\left({ }^{2}\right)$. Um pouco mais tarde dizia-se que "[...] Falta a estes senhores a generosidade, que sobejou ao Serenissimo Duque

${ }^{(2}$ ) Francisco Manuel de Melo, D. Teodósio Duque de Bragança, Porto, Liv. Civilização Ed'a 1944, p. 199. António Caetano de Sousa repetiu o dito de D. Teodósio II: "que os seus predecessores havião tido o cuidado de ajuntar, e exaltar a sua grandeza, e que agora, à sua pessoa só tocava trabalhar para conservar a honra, e estado, que elles havião estabelecido", António Caetano de Sousa, História Genealógica da Casa Real Portuguesa, t. VI, Coimbra, Atlântida Livraria Editora, p. 279 (doravante citado apenas como HGCRP). 
D. Theodosio [...] o qual convidado por EIRey Filipe III de Castella, quando veyo a Portugal na era de 620 que lhe pedisse mercês, respondeo com palavras dignas de cedro, e de laminas de ouro: Vossos e nossos avós encheraõ nossa casa de tantas mercês, que não me deixaraõ lugar para aceitar outras. Em Portugal ha muitos fidalgos pobres de mercês, e ricos só de merecimentos, em quem V. Magestade póde empregar sua Real magnificencia $[\ldots]^{\prime \prime}\left({ }^{3}\right)$.

Esta questão merece, todavia, uma reflexão um pouco mais detalhada. A nosso ver ela deverá ser feita pelo cruzamento dos dados disponíveis sobre a política da Casa referente à salvaguarda $\mathrm{e}$ acrescentamento dos seus direitos e privilégios com os diversos períodos históricos. É que, com excepção de Francisco Morais Sardinha, os cronistas brigantinos redigiram os seus textos após 1640 . E este facto exige por si só alguma preocupação crítica na descodificação das representações criadas sobre a postura política dos duques de Bragança. Essa aura de desinteresse face às mercês da monarquia dificilmente adere aos factos hoje conhecidos para a centúria de quinhentos, sobretudo se se ponderar também o comportamento dos duques em 1580.

De facto, ao longo do século XVI a Casa de Bragança contraiu o espaço físico do seu senhorio. As poucas terras com jurisdição cível e crime que the foram outorgadas não tinham dimensão geográfica, nem importância económica, demográfica ou militar significativa, foram doadas com um estatuto precário (em vidas) $\left({ }^{4}\right)$ e não compensaram, portanto, os concelhos que, por diversos motivos e várias formas, a Casa alienou( $\left(^{5}\right)$. Obtiveram, no entanto, uma série

(3) Arte de Furtar, ed. crítica, introd. e notas de Roger Bismut, IN/CM, 1991, cap. XLVI, p. 280.

$\left({ }^{4}\right)$ Por ocasião do primeiro casamento de D. Teodósio I, foram-lhe doados os concelhos de Vale de Nogueira e Vila Franca, no termo de Bragança; em 1602 o consórcio de D. Teodósio II valeu-lhe a doação de Vila do Conde.

(5) Os concelhos da Vidigueira e Vila de Frades foram vendidos, em 1519, a Vasco da Gama; a jurisdição e padroados de Vila Alva e Vila Ruiva foram escambadas com D. Rodrigo, conde de Tentúgal, por rendas da dízima do pescado de algumas localidades e pela quinta de Andaluz em 1520; o ducado de Guimarães foi integrado no dote de casamento de D. Isabel, filha de D. Jaime, com o infante D. Duarte em 1536; as beetrias do Marão, após o seu confisco em 1483 , não voltaram à Casa, sendo, porém, compensadas pecuniariamente. Cf. António Caetano de Sousa, HGCRP, t. IV, passim e A. 
muito ampla de novos privilégios ou a confirmação de privilégios concedidos anteriormente que thes garantiam condições excepcionais na administração do senhorio. Ou seja, preferiu-se a manutenção e o reforço do leque de instrumentos de intervenção senhorial e dos signos de distinção social, em detrimento do acrescentamento da base territorial do senhorio.

A correspondência mantida com Filipe II e com os seus agentes revela, por seu turno, a amplitude das contrapartidas exigidas nas negociações efectuadas no ano de $1580\left(^{6}\right)$. Se, por um lado, o desejo livremente expresso de negociar revelava algum desinteresse pela tomada de poder ou, pelo menos, o reconhecimento implícito da incapacidade de confrontar com sucesso o outro candidato, o resultado prático foi a renúncia voluntária dos direitos de sucessão na Coroa

M. Hespanha, As Vésperas de Leviathan. Instituições e Poder Político. Portugal séc. XVII, vol. II, Lisboa, ed. Autor, 1986, passim.

${ }^{(}{ }^{6}$ O fundamento negocial da duquesa D. Catarina era a resolução do impasse sobre a sucessão ao trono de Portugal por via de "concerto e transacção" que era uma das três modalidades que ela apontava como sendo uso seguir-se quando havia dúvidas sobre tais matérias (as outras duas eram a justiça - e à data do início das negociaçōes essa ainda não havia sido determinada por quem de direito - e a via das armas - que Filipe II se prestava a utilizar, mas que a duquesa rejeitava). É claro que as posições dos dois pretendentes eram opostas, uma vez que a esta análise o monarca castelhano contrapunha não haver dúvidas sobre a legitimidade dos seus direitos o que o levava a entender não carecer da renúncia dos direitos sucessórios da duquesa para, legitimamente, tomar posse do Reino de Portugal. Nesta óptica, o que D. Catarina propunha como contrapartidas contratuais, Filipe II entendia serem mercês graciosas (disse-o, de resto, em carta datada de 10 de Novembro de 1580 "se havran de contentar con mostrarles que aquello procede de mi liberalidad y no de ningun genero de obligacion"). Ou seja, segundo a perspectiva expressa do Habsburgo, a negociação com a Casa de Bragança assemelhar-se-ia, assim, às outras já concretizadas com várias casas senhoriais portuguesas. Daí o cuidado posto pelos agentes brigantinos em clarificar a possibilidade (e as eventuais hipóteses de sucesso) que os duques tinham de fazer valer os seus direitos, uma vez que a justiça ainda se não pronunciara sobre a matéria. Cf. a correspondência publicada por Queirós Velloso em O Interregno dos Governadores e o Breve Reinado de D. António, Lisboa, Academia Portuguesa de História, 1953, "Apêndice Documental", p. 207 ss.. A citação, supra, da carta de 10 de Novembro reporta-se à p. 271. 
portuguesa. A lista das propostas brigantinas para efectivar o acordo é a todos os títulos clarificadora da estratégia política da Casa, sobretudo se for tomada como um inventário de desejos e ambições senhoriais. Agregando-os em tópicos teremos um primeiro grupo relativo à definição do destino dos filhos; um segundo que agrupa a simbólica da "honra" (titulação, tratamentos, armas da Casa, serviços e presença na corte régia); um terceiro que integra as medidas de ampliação das prerrogativas excepcionais já detidas pelos Bragança (apresentação de comendas, isenção de direitos de importação de especiarias indianas, por exemplo) e um último que inclui propostas de significativo alargamento das jurisdições e dos direitos senhoriais carregadas de simbolismo (doação de novas terras de juro e herdade - quase todas com tradição de pertença a Casas de infantes -, maior autonomia jurisdicional e novas rendas).

Os dados mais interessantes neste leque de pedidos quase inviáveis são tanto o esforço para obter direitos régios juridicamente inalienáveis $\left({ }^{7}\right)$, quanto a perseguição de bens simbólicos ou (como veremos depois) através do jogo de alianças matrimoniais e dos privilégios de tratamentos, garantir um estatuto social ímpar para a Casa, não já apenas no contexto português, mas também no ibérico.

A imagem de absoluta primazia que a Casa detinha no espaço social português era relativamente consensual. Assim o entendiam e o expressavam eles mesmos: a) independentemente da existência de outros duques e dos destinatários das missivas, os titulares da Casa assinavam e eram identificados em textos simplesmente como "ho duque" $\left({ }^{8}\right)$; b) segundo as palavras de um dos próprios (testamento

(7) Eram, por exemplo, os casos da doação das sisas das terras, da outorga do privilégio de não entrada dos provedores no senhorio, da concessão do mestrado da ordem de Avis, dos privilégios relativos à confirmação dos hábitos e comendas da sua apresentação. Cf. o parecer de Nuno Álvares Pereira, sobre estas matérias in Queirós Velloso, O Interregno dos Governadores..., pp. 263-265.

${ }^{8}$ ) Este tópico era de tal modo relevante que foi objecto de destaque na carta em que o duque de Bragança escreveu ao rei Filipe II insurgindo-se contra algumas das disposições tomadas na Lei das Cortesias de 1597. Sugerira o rei que os senhores de títulos acrescentassem na assinatura o lugar da terra de onde tinham o título. Como era contrário à prática seguida pelos duques de Bragança, este clarificou que "conforme a isto o Duque não determina fazer mudança no seu sinal, nem ha que fas nisto contra a Ley", António 
do duque D. João I, em 1583), estipulava "Ao Duque de Barcellos meu filho mando que de tal maneira proceda sempre no serviço delRey meu Senhor que ninguem possa fazer comparaçam com elle..." $\left({ }^{9}\right)$. Sempre que se sentiam desafiados, impunham aos menos convictos essa imagem, contribuindo para tal a força do seu poder e das suas conexões. E essa capacidade advinha-lhes, em grande medida, da conivência da própria Coroa: a rainha D. Catarina era a primeira a considerar publicamente o duque de Bragança como "o principal sr. deste reyno" $\left({ }^{10}\right)$. Mas veremos melhor estas questões a propósito das querelas sobre tratamentos e precedências.

Note-se que a preservação desse estatuto de preeminência social implicava uma permanente atenção à evolução e à força dos contextos políticos, sociais e simbólicos. Quaisquer inovações nos modelos organizativos e de representação da Casa Real, nas formas de gestão e de administração dos recursos pela monarquia deveriam (tinham de) ser acompanhados no tempo e na escala possível pela Casa de Bragança, sob pena de aceitar o alargamento da distância entre a Casa e a Coroa e ver encurtadas as distinções que a separavam da principal nobreza do Reino. O papel da analogia, própria da lógica da semelhança aristotélica, conceito que para Foucault é caracterizador da cultura ocidental até finais do século XVI $\left({ }^{11}\right)$, também desempenha um papel fulcral no sistema de representações brigantino. A participação no sistema de símbolos políticos da monarquia criava imagens de grandiosidade e opulência que eram interiorizadas e depois reproduzidas como valor da Casa $\left({ }^{12}\right)$. Ou seja, a convicção da

Caetano de Sousa, Provas da História Genealógica da Casa Real Portuguesa, Coimbra, Atlândida - Livraria Editora, t. IV, P. $1^{\text {a }}$, p. 371 (doravante citado apenas como Provas...).

(9) António Caetano de Sousa, Provas..., t. IV, P.12, p. 401.

(19) Citação in Maria do Rosário de S. T. B. de Azevedo Cruz, As Regências na Menoridade de D. Sebastião. Elementos para uma História Estrutural, vol. I, Lisboa, IN/CM, 1992, p. 300.

('1) Michel Foucault, As Palavras e as Coisas. Uma Arquelogia das Ciências Humanas, Lisboa, Edições 70, 1991 (edição original de 1966), maxime, pp. 73 89.

$\left.{ }^{(12}\right)$ Exemplos particularmente evidentes são os privilégios de nobilitação e a adopção dos usos cerimoniais da Casa Real. Como se verá, embora não se consiga estabelecer com exactidão a origem desses privilégios, não havia qualquer discussão sobre a legitimidade do seu uso. 
hierarquia das semelhanças colaboraria tão eficazmente na reprodução da diferença social, quanto os seus efectivos suportes materiais (títulos, privilégios e poderes de "mando", por exemplo).

Uma análise sumária do tipo de mercês e de distinções usufruído pelos Bragança comprova o carácter invulgar de tão grande concentração de privilégios e de direitos excepcionais numa só casa senhorial. Mesmo do ponto de vista da história comparada talvez seja difícil encontrar uma outra casa senhorial que, para o mesmo período cronológico, proporcionalmente à dimensão do reino e face ao quadro jurídico vigente, dispusesse de tão amplas e quase régias prerrogativas. Um dos aspectos mais interessantes desta situação peculiar, refere-se à pacífica e sempre negociada coexistência que ao longo dos séculos XVI e XVII a Coroa manteve com a Casa, sobretudo se atendermos ao facto de, em outras monarquias, casas e linhagens com muito menor quantidade e qualidade de poder terem entrado em colisão com os respectivos soberanos.

\section{Estratégias matrimoniais da Casa de Bragança}

As escolhas matrimoniais e o destino que os duques de Bragança encontraram para os seus diversos descendentes merecem uma atenção particular. Neles se depositam e se expressam as estratégias de alianças que os duques aceitavam fazer e, por exclusão, todas aquelas que recusavam. Uma breve comparação entre as opções de casamento feitas no século XV e nos séculos XVI e XVII confirma - que se disse anteriormente sobre as estratégias reprodutivas da Casa. Enquanto na centúria de quatrocentos se procurou quase sistematicamente casar todos os descendentes da Casa - o que não apresentou qualquer excepção para os varões $\left({ }^{13}\right)$ - , nos séculos XVI e XVII os investimentos matrimoniais reduziram-se significativamente - dos vinte e quatro filhos que chegaram a idades núbeis e exceptuando os cinco sucessores, só oito casaram. Os celibatários foram encaminhados para carreiras eclesiásticas (cinco) ou não tomaram qualquer estado (seis, dos quais cinco eram varões).

(13) Mafalda Soares da Cunha, Linhagem, Parentesco e Poder. A Casa de Bragança (1384-1483), Lisboa, Fundação da Casa de Bragança, 1990, pp. 2356. 
Esta alteração na intensidade de recurso ao matrimónio correspondeu igualmente à substituição de uma lógica linhagística por uma lógica de "casa" $\left({ }^{14}\right)$. Ao alargamento dos recursos detidos pela linhagem (acumulação de recursos jurisdicionais pelo casamento de filhos com sucessoras de casas titulares com amplos senhorios, mas também diversificação de alianças entre a grande nobreza do Reino), sucedeu-se uma lógica de distinção social que é comprovável pelo tipo de selecção de cônjuges para os primogénitos. Se excluirmos os dois casos das segundas núpcias dos $4^{\circ}$ e $5^{\circ}$ duques de Bragança, que parecem obedecer mais a inclinações pessoais que a qualquer estratégia reprodutiva, verificamos que nos cinco casamentos restantes a Casa optou ou por alianças com Grandes de Castela, ou dentro da sua própria linhagem ou ainda na Casa Real. Este padrão de escolha reproduziu-se de modo bastante similar com os demais descendentes. Dos oito casamentos concertados, quatro incidiram em casas de titulares castelhanos, dois com a casa dos marqueses de Ferreira (do mesmo grupo linhagístico que os Bragança) um com a dos marqueses de Vila Real (com quem a Casa tinha também tradição de alianças matrimoniais) e um com a família real (cf. Quadro Genealógico - A Casa de Bragança, sécs. XVI/XVII).

Quer isto dizer que se percebe existir uma estratégia clara de evitar alianças com a nobreza portuguesa. Quando tal ocorreu seleccionou-se a casa mais antiga e de melhor linhagem - Vila Real - ou então reforçaram-se laços com a própria parentela - Ferreira/ Tentúgal. Casar fora, em Castela, era a estratégia da monarquia e também a que se afigurou mais conveniente para a Casa de Bragança. Evitavam-se excessos de proximidade e de familiaridade com a nobreza do reino e conseguiam-se uniões socialmente aceitáveis, 0 que dificilmente ocorreria entre o mercado matrimonial dos titulares portugueses. Dizia o duque D. Jaime "bem visto tinha quão poucos casamentos neste reino havia para elles [seus filhos]" $\left.{ }^{15}\right)$.

(14) Sobre a definição dos conceitos de linhagem e "casa" ver, respectivamente, Bernardo Vasconcelos e Sousa, Os Pimentéis. Percursos de uma Linhagem Medieval Portuguesa (Séculos XIII-XIV), Lisboa, FCSH-UNL, 1995 (dissert. de doutoramento, mimeo), pp. 366-369 e bibliografia citada e Nuno G. Monteiro, "Poder Senhorial, Estatuto Nobiliárquico e Aristocracia", História de Portugal, dir. José Mattoso, vol. IV, O Antigo Regime (1620-1807), coord. A. M. Hespanha, p. 365.

(15) Carta ducal de 1630 , transcrita na integra em Fernando Palha, $O$ 


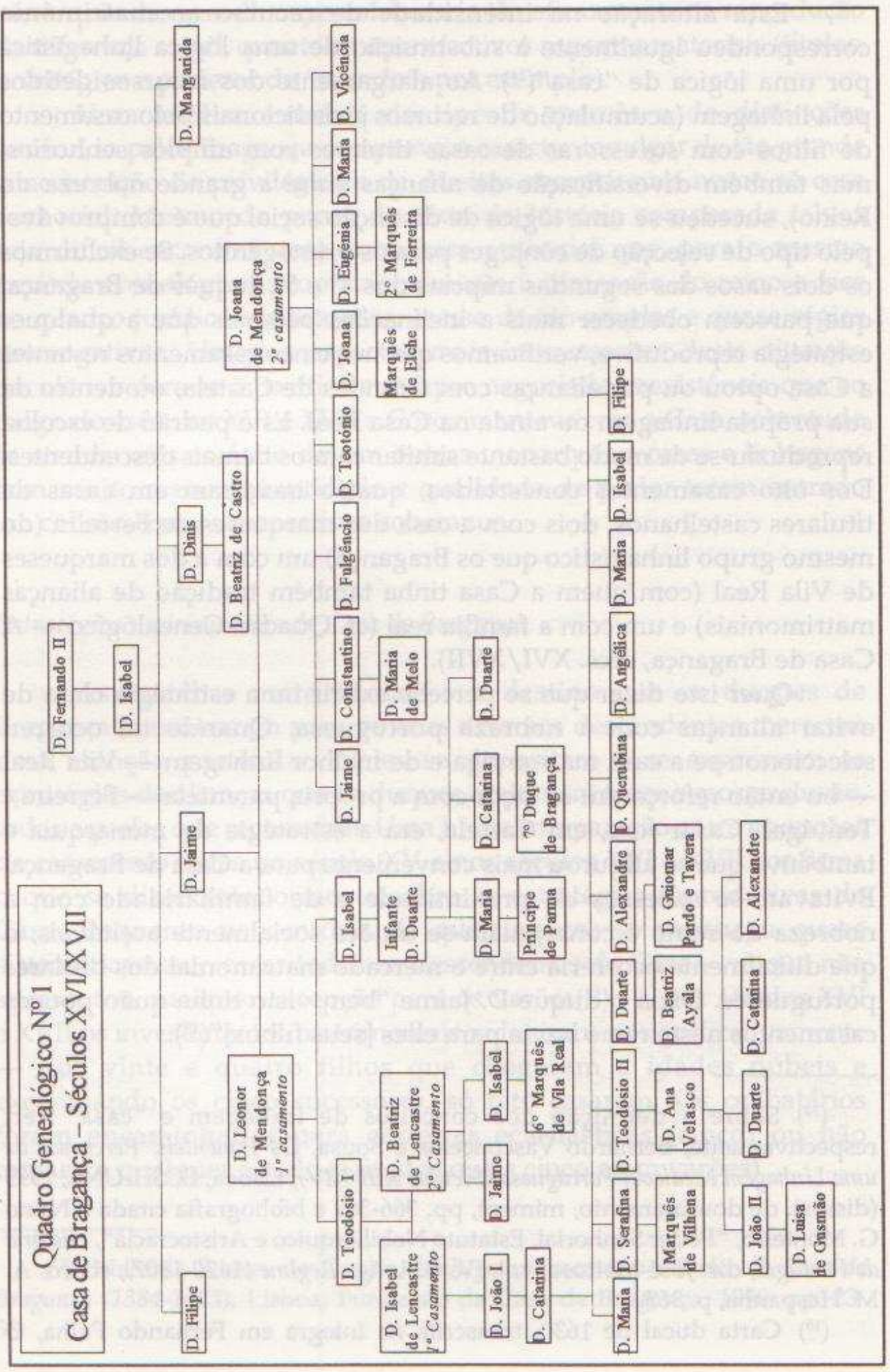


Internamente a melhor opção era mesmo o casamento com membros da família real. Tal ocorrera no século anterior e voltou a repetir-se no século XVI. O preço de tais uniões era alto, mas servia as estratégias simbólicas da Casa de Bragança e, ao que parece, também as apetências matrimoniais da Casa Real.

Este breve apontamento esboça tendências de actuação que, naturalmente, escondem os diversos interesses conjunturais que a negociação de cada uma destas uniões suscitava. Embora na economia deste discurso não se justifique um grande aprofundamento do nível de análise, julgamos pertinente apresentar alguns exemplos ilustrativos do tipo de problemas e de interesses envolvidos nos acordos matrimoniais. Um será o do acerto do casamento de D. Isabel, filha do duque D. Jaime, com o infante D. Duarte. O outro, as negociações matrimoniais imediatamente posteriores a 1580 , com particular destaque para o caso de D. Teodósio II.

A hipótese de unir D. Isabel a um dos filhos mais novos de D. Manuel parece ter colhido o duque D. Jaime de surpresa. A proposta terá nascido de D. João III e o medianeiro foi o conde da Castanheira. Aparentemente a decisão final dependia do montante do dote que o duque poderia disponibilizar. A primeira proposta de D. Jaime terá desagradado ao monarca, mas a rejeição régia agravou o duque que sentiu que o processo de decisão não visava o acrescentamento da sua honra, mas o serviço directo da Coroa. A carta que, por isso, escreveu ao monarca, em 1530 , constitui um documento extraordinariamente expressivo, quer do que o duque entendia deverem ser as relações da Coroa com a sua Casa, quer do que se jogava nas alianças matrimoniais $\left({ }^{16}\right)$.

Muito sinteticamente dir-se-ia que D. Jaime adoptara uma posição aproximada da do seu antepassado Nuno Álvares Pereira, a propósito do concerto de casamento da sua única filha D. Beatriz. Este rejeitara a proposta de união com o herdeiro do trono que sabia conduzir à extinção da sua recém constituída Casa. D. Jaime não se prestava a sacrificar significativamente a sua em prol da renovação dos laços com a família real. Dizia-o, de resto, aberta e arrogantemente

Casamento do Infante D. Duarte com D. Isabel, Lisboa, Imprensa Nacional, 1881, p. 35 .

${ }^{16}$ ) Fernando Palha, O Casamento do Infante D. Duarte com D. Isabel..., pp. 26-35. 
"e se vossa alteza bem olhou que eu respondi a D. Antonio, quando me da vossa parte fallou, bem devêra de ver que eu não havia de dar a minha filha cousa que me houvesse de desfazer nem destruir, porque eu lhe disse logo, que eu queria ainda mór bem a mim que a meus filhos, após mim a minha casa mais que a elles, e por isso não havia de fazer cousa que desfizesse em meu filho herdeiro e na casa que the havia de ficar, e porque tinha esta tenção estava bem fora de desejar para minha filha marido a que eu houvesse de beijar a mão, e que queria antes casa-la com um homem qua m'a beijasse a mim para o ter em minha casa para me aproveitar e servir d'elle, e faria conta de lhe buscar de comer como hei de buscar para estoutros filhos machos..." $\left({ }^{17}\right)$. O maior ressentimento advinha, parece, da comparação que o rei teria feito a propósito do montante do dote explicitado "Vossa alteza me rechaçou tudo, despresando-o tanto que me comparastes com João da Guarda, e com a filha de Ruy de Mello, e com a filha de D. Francisco de Almeida, viúva de outro marido" acrescentando que "os casamentos que agora são grandes são de villãos ou christãos novos que por remir sua villania ou judearia quando querem haver pessoas de differente estado que são tão baixos que se querem vender por dinheiro, estes taes os compram, ou é de pessoas que vem da India ricos de roubar vossa alteza, que assim como lhe custa pouco a ganhar, tem em pouca conta de o dar". Inventariava de seguida os dotes concedidos nos diversos casamentos de infantas no século XV para comprovar a justeza do que oferecera ao monarca. Aduzia de seguida os méritos e a estima internacional que a sua Casa detinha através de uma lista de propostas de casamento que the haviam sido feitas a ele, D. Jaime, quando se negociara a sua primeira união - as realizadas pelo imperador Maximiliano e pelo soberano inglês -, justificando a decisão a que se chegara pelo interesse de D. Manuel em atrair o duque de Medina Sidónia para a sua órbita motivado pela questão de Gibraltar ("e comtudo el-rei meu senhor [...] por haver logo em breve o dinheiro de meu casamento e o duque meu sogro por servidor, que n'ella lhe podia muito servir concluiu o meu casamento...").

A negociação não ficou por aqui. Interrompeu-se com as delongas do soberano, reatando o duque outras oportunidades. Uma $\left(^{(17)}\right.$ Fernando Palha, O Casamento do Infante D. Duarte com D. Isabel..., p.
27, (o itálico é nosso). 
delas era com o conde de Benavente $\left({ }^{18}\right)$, outra com o conde de Oranha. Mas o necessário assentimento régio para esses acordos não foi dado. Protelou-se, assim, a questão até depois da morte de D. Jaime. Com D. Teodósio I veio por fim, mas não imediatamente, o acordo. E este correspondia bem à medida das expectativas do rei e não da Casa: largava-se o ducado de Guimarães e uma série de outras rendas. O casamento ocorreu em 1536, em Vila Viçosa; a contrapartida imediata que a Casa dele retirou foram as soberbas festas, realizadas com a pompa e circunstância que se conhece $\left({ }^{19}\right)$.

Em 1580, a proposta que encabeçava as contrapartidas pedidas pela renúncia dos direitos sucessórios era a de casar a filha mais velha da duquesa com o Príncipe herdeiro de Castela. Como dote não se oferecia senão o direito de D. Catarina ao trono. Como bem entenderam os conselheiros de Filipe II, tal proposta traria grandes vantagens à Casa de Bragança, mas muitos inconvenientes à monarquia, uma vez que faria o duque de Barcelos cunhado do rei de Espanha, situação que desgostaria não só os castelhanos, como também a própria nobreza portuguesa uma vez que "a grandeza e vanidad de la casa de Bergança les es odiosissima y creçiendola por este camino se les haria intolerable" $\left({ }^{20}\right)$. Embora irrealizável, só o equacionar dessa hipótese revela com bastante clareza o intuito de criar junto da Coroa castelhana uma situação paralela àquela que a Casa de Bragança construíra com os reis portugueses. Ou seja, entretecer uma rede de parentesco com a família real que a colocasse numa posição de indiscutível preeminência face aos Grandes de Castela. Neste contexto, compreende-se que a oferta matrimonial que, anos mais tarde, a duquesa D. Catarina recebeu de Filipe II, não servisse os interesses da Casa. O risco de um dote que cercearia os proventos do ducado, não compensava a honra da união, tanto mais que qualquer possibilidade de descendência estava fora de causa.

Os sucessivos e fracassados arranjos matrimoniais de D. Teodósio II ao longo das duas últimas décadas do século XVI foram,

${ }^{(18)}$ Carta ducal, datada de Évora, 1533, ao Condestável de Castela sobre o casamento de D. Isabel com o conde de Benavente, BNM, Ms. $638, n^{\circ} 50$, fl. 123. t. VI.

(19) BNL, cód. 1544, BNL, cód. 484 e António Caetano de Sousa, HGCRP,

${ }^{(20)}$ Carta do conde de Portalegre in Queirós Velloso, O Interregno dos Governadores..., p. 239. 
em grande parte, fruto do excesso de vantagens que a Casa procurara anteriormente. Surgira a hipótese de o casar com a filha do arquiduque Carlos (duque de Estíria e Carníola), em 1593, que se gorou pelo facto de Filipe II pensar casar o príncipe herdeiro nessa mesma casa e não querer que o rei de Espanha ficasse cunhado do Bragança $\left({ }^{21}\right)$. Em 1598, levantou-se a possibilidade do consórcio com Maria de Médicis, herdeira do grão duque da Toscânia, que acabou por não se concretizar, porque esta veio a casar com o rei de França $\left({ }^{22}\right)$. Eram, todas elas, alianças possíveis para casas reais; excessivas para a casa de um vassalo da Coroa. Filipe III acabou por sugerir a união com D. Ana de Velasco, filha do Condestável de Castela e $3^{\circ}$ duque de Frias. Pese embora a flagrante discrepância face às anteriores propostas, esta solução foi levada avante. O duque de Bragança contava já 32 anos e era fundamental que tomasse estado e assegurasse a sucessão da Casa. As capitulações matrimoniais tiveram, por isso, lugar em 1602.

A atenção com que os monarcas castelhanos seguiram os posteriores acertos de casamento dos membros da Casa de Bragança entronca-se no mesmo tipo de preocupações. Importava-lhes que estruturassem e reforçassem os laços com a nobreza castelhana e não que criassem alianças externas. Pelo menos era essa a plausível lógica que os cronistas da Casa, nomeadamente António Caetano de Sousa, emprestaram à política dos Áustria para com a Casa de Bragança. E tal estratégia havia já sido consubstanciada nos acordos de casamento de D. Serafina com o Duque de Escalona e Marquês de Vilhena (1593) e de D. Duarte com a sucessora do condado de Oropesa $(1596)\left({ }^{23}\right)$.

Independentemente das circunstâncias específicas em que se realizou cada um dos concertos matrimoniais e dos eventuais interesses que a Coroa neles teria projectado, o que importa efectivamente sublinhar - e que não decorre linearmente da política de casamentos promovida pelos monarcas castelhanos após 1580 - é a estratégia de distinção e, portanto, de distanciação face ao conjunto da nobreza que eles sempre revelaram. Deve-se ainda destacar que as sucessivas intercepções das trajectórias dos Bragança com as da família real, que a Coroa portuguesa não apenas admitiu como até

(21) António Caetano de Sousa, HGCRP, t. VI, pp. 194-198.

$\left({ }^{22}\right)$ António Caetano de Sousa, HGCRP, t. VI, pp. 204-208.

${ }^{(23)}$ António Caetano de Sousa, HGCRP, t. IX, p. 3 ss.. 
procurou, não se repetiram em nenhuma outra casa senhorial portuguesa $\left({ }^{24}\right)$.

Concessão de nobreza e cerimonial doméstico

Todos os cronistas da casa foram unânimes em destacar quer a excepcional prerrogativa brigantina de poder conferir nobreza quer a equivalência existente entre os foros, as moradias e os ofícios palatinos da Casa de Bragança e os da Casa Real. Divergiram quanto às causas e quanto ao momento da sua introdução. Segundo Francisco Morais Sardinha, a concessão de tais privilégios seria quase coincidente com a formação da Casa Ducal, datando-a do tempo do $1^{\circ}$ duque, D. Afonso $\left({ }^{25}\right)$, enquanto D. Tomás Caetano de Bem explicou a adopção deste "estilo" como uma mercê que acompanhou a aliança matrimonial entre D. João I, $6^{\circ}$ duque de Bragança e D. Catarina, membro da família real $\left({ }^{26}\right)$. Outros há que o situaram no tempo em que $04^{\circ}$ duque, D. Jaime, por ter sido jurado herdeiro do trono de Portugal, se apropriara de um conjunto amplo de prerrogativas reais $\left({ }^{27}\right)$.

Embora com espessura temporal diferenciada, os sentidos das justificações apontadas pelos autores são, afinal, similares. Indiciam a apropriação de insígnias régias, cuja doação só pode ser explicada por contextos de trajectórias tangentes entre a Casa e a realeza. Exploram e sublinham, para mais, a imagem de grande proximidade

(24) O casamento do infante D. Fernando com a sucessora da Casa de Marialva, no início do século XVI, teve, como se sabe, intuitos claros de anexação dessa Casa ao património régio, e não a criação de redes de aliança como ocorreu com os Bragança.

(25) BNL, cód. 107 - Francisco de Morais Sardinha, Antiquissimo Parnasso novamente achado, e descuberto em Villa-Viçosa de que he Apollo o Excellentíssimo Princepe $D$. Theodosio $2^{\circ}$ deste nome...\& E assi dos varões illustres que nella nascerão, e florecerão em armas em letras e poesia, com outras muitas couzas a proposito no discurço deste livro (1618), fl. 49.

${ }^{(26)}$ BNL, Ms. $4, n^{\circ} 1$, fl. 113v.

(27) Cf. Francisco Manuel de Melo, D. Teodósio..., pp. 119-120; António de Oliveira Cadornega, Descrição de Vila Viçosa, introd. de Heitor Gomes Teixeira, Lisboa, IN/CM, 1982, p. 52 e Alvaro Ferreira de Vera, Origem da Nobreza Política, Blasões de armas, appellidos, cargos, \& titulos nobres, Lisboa, Mathias Rodriguez, 1631, fl. 24. 
com a dinastia reinante em Portugal, construindo-lhe uma identidade magnificente, quase real.

Era um jogo de semelhanças cuja realidade se aceitava. A Casa de Bragança retirava dele inequívocas vantagens; uma delas foi ter conseguido impor critérios de consideração social sobre o prestígio associado ao seu serviço aproximados do serviço na Casa Real. Um dos mais significativos efeitos desse fenómeno foi o reforço da capacidade de atrair clientelas e de consolidar honradamente essas mesmas dependências pessoais. Significa isto que as possibilidades de nobilitação, de acrescentamento de foro nobiliárquico e, sobretudo, - relevo social conferido aos serviços de âmbito doméstico the permitiram manter uma "familia" onde se incluíam membros de importantes linhagens fidalgas do Reino. Estas características da composição social dos seus cortesãos conferiam, por seu turno, consistência ao modelo de etiqueta adoptado pela corte ducal, que como foi sublinhado pelos seus cronistas seguia o "estilo" cerimonial dos Áustrias $\left({ }^{28}\right)$.

A atenção que os duques emprestaram à actualização dos sígnos de representação do poder explica, igualmente, a preocupação em criar uma capela privativa dotada de privilégios que pouco a diferenciavam da própria capela real. Se a decisão de D. Jaime de incorporar um espaço para a celebração do sagrado no interior do novo edifício palaciano não apresenta singularidade particular, 0 esforço constante para ampliar os privilégios e a dignidade cerimonial do culto $\left({ }^{29}\right)$ deve ser compreendido como parte integrante do jogo de similitudes com a Casa Real.

${ }^{(28)}$ "A Serenissima Casa de Bragança, para em tudo ser singular, e superior a todas, as que não logravão as distinçoens de Soberania, até ao Ceremonial practicado na Sua Corte, ostentava a Sua elevada grandeza. Como Soberana na Sua origem, o Seo Tracto em tudo parecia, era Real. [...] e o Seo Paço, não só em tudo era sumptuoso, e magnifico; mas Servido da mesma sorte, que a Real Caza...", D. Tomás Caetano de Bem, BNL, Ms. 4, $n^{\circ} 1$, fl. 103v.

(29) Para que tal fosse possível os duques de Bragança tiveram que criar mecanismos de pressão constantes em Roma - agentes na cúria pontifícia e somas significativas - no sentido de adquirir as necessárias autorizações canónicas. $\mathrm{O}$ esforço foi bem sucedido, uma vez que a Casa Ducal foi sucessivamente obtendo breves e bulas papais que the asseguravam amplos privilégios de culto e engrandecimento do ritual até, finalmente, obterem 


\section{Hábitos e comendas da Ordem de Cristo}

O acesso aos hábitos e às comendas da Ordem de Cristo representava um elemento fundamental na hierarquia do prestígio social da época. Assim a possibilidade de apresentação de comendas da ordem de Cristo adquirida pelos Bragança constituiu um dos seus maiores trunfos políticos. Evidenciava, desde logo, o poder para alargar e institucionalizar os recursos distribuídos pela Casa Ducal $\left({ }^{30}\right)$, mas constituía um outro tópico demonstrativo da sua notável capacidade de adaptação aos novos contextos sociais e simbólicos de exercício da liberalidade. Relembremos que a aquisição deste direito sucede de perto a criação das comendas novas por D. Manuel e antecede o seu controlo directo pela monarquia, só eficazmente garantido depois da união dos mestrados das ordens à Coroa em 1551. Recorde-se ainda que a linhagem rival da Casa de Bragança (os Lencastre da futura Casa de Aveiro) superintendia, desde finais do século XV, as ordens de Santiago e de Avis através da acumulação dos mestrados dessas duas milícias em D. Jorge de Lencastre, filho bastardo de D. João II. A possibilidade de os Bragança também obterem algum controlo sobre os recursos das ordens atenuava essa vantagem comparativa o que era decisivo para a demarcação do espaço social pretendido para a sua Casa.

O facto de, em 1580, D. Catarina ter pedido a Filipe II os direitos de padroado e de apresentação em vinte outras comendas das ordens de Avis e de Cristo e de ter, igualmente, pretendido isenção do controlo das qualidades de sangue dos candidatos por si apresentados na Mesa da Consciência e Ordens $\left({ }^{31}\right)$ demonstra bem a importância que este recurso assumia na economia da liberalidade ducal. Embora desconheçamos casos concretos de indeferimento destas apresentações brigantinas, o que aparenta significar que em termos práticos 0 consentimento era quase tácito, simbolicamente a questão revestia-se

paridade, em matéria de autonomia e dignidade, com as igrejas catedrais e as colegiadas e isenção do ordinário territorial. Ver o estudo de José Augusto Alegria, História da Capela e dos Santos Reis de Vila Viçosa, Lisboa, Fundação Calouste Gulbenkian, 1983 e a documentação transcrita em António Caetano de Sousa, Provas..., t. IV.

$\left({ }^{30}\right)$ Cf. Mafalda Soares da Cunha, "Institucionalização de Recursos Distribuíveis. Hábitos e Comendas da Ordem de Cristo da Apresentação da Casa de Bragança", Callipole, $\mathrm{n}^{\circ}$ 3-4, 1995-1996, pp. 27-35.

(31) Queirós Velloso, O Interregno dos Governadores..., p. 260. 
de grande importância. Se o pedido fosse aceite ser-lhes-ia reconhecido paridade com a própria Coroa em matéria de escolha dos futuros cavaleiros, o que lhes facultaria um outro mecanismo de concorrência directa com a monarquia e de distanciamento das demais casas senhoriais. Diga-se, no entanto, que mesmo os privilégios de apresentação já detidos não tinham equivalência em qualquer outra casa senhorial europeia.

Formas de tratamento, precedências e ausência da corte régia

Alguns dos tópicos anunciados neste título foram já objecto de análise mais detalhada em outro trabalho $\left({ }^{32}\right)$. Por isso, importa apenas desenvolver os domínios em que a Casa mobilizou esforço, atenção e influência para obter primazia na partilha e na apropriação dos signos de distinção social. Referimo-nos concretamente às numerosas variantes das polémicas de precedências e de formas de tratamento que opuseram, intermitentemente, os duques de Bragança aos de Aveiro e a D. António, Prior do Crato e os seus irmãos e parentes a outros tantos grandes senhores do reino.

Não que este tema fosse um exclusivo do topo da hierarquia nobiliárquica. Afligiu, de forma generalizada, todos aqueles que tinham, ou sentiam que tinham, direitos e deveres de representação. O poder revelava-se em signos visíveis. Por isso, defender precedências era preservar - ou conquistar - determinadas posições na hierarquia social. Em última análise, tratava-se da defesa da "honra" e esta era um dos mais difusos, mas também dos mais importantes bens que valia a pena salvaguardar $\left({ }^{33}\right)$. E esse conceito conferia-lhes

${ }^{(32}$ Cf. Mafalda Soares da Cunha, As Redes Clientelares da Casa de Bragança..., sobretudo cap. I, ponto 2.

${ }^{(33)}$ Cf, o estudo clássico de José Antonio Maravall, Poder, Honor y Élites en el Siglo XVII, $2^{\text {a }}$ ed., Madrid, Siglo XXI, 1984 ( $1^{\text {a }}$ ed. 1979) e, mais recentemente o trabalho de Kristen B. Neuschel, Word of Honor. Interpreting Noble Culture in Sixteenth-Century France, Ithaca e Londres, Cornell University Press, 1989. O tópico "honra" tem, porém, sido objecto de outras abordagens, com perspectivas um pouco diversas, mas que ilustram tanto a polissemia do conceito (cf. por exemplo, Claude Chauchadis, Honneur, Morale et Societé dans l'Espagne de Philipe II, Paris, CNRS, 1984), quanto às possibilidades da sua instrumentalização na luta política (cf., entre outros, Richard Cust, "Honour and Politics in Early Stuart England: The Case of Beaumont v. Hastings", Past and Present, ${ }^{\circ} 149,1995$, pp. 57-94). 
uma sensibilidade especial ao poder simbólico, transformando este em "both a motor and a goal of public life" $\mathrm{e}^{\prime \prime}\left({ }^{34}\right)$.

Os conflitos sobre essas matérias tendiam, por isso, a ser longos e a reacender-se periodicamente - $a$ intransigência era o único mote de quem se sentia agravado. A Coroa, árbitro último de todas estas querelas procurava, com o auxílio da justiça - jurisprudência, sobretudo - dar a cada um o que lhe era devido. Tarefa difícil porque a capacidade argumentativa dos envolvidos era quase inesgotável e não havia legislação suficientemente clara sobre a matéria. Eram os diferentes e diversos casos que iam surgindo que estabeleciam os precedentes, as balizas e as fronteiras das tomadas de decisão futuras. Da consciência desse facto - do peso conferido à tradição nos processos de decisão - radicava o empenhamento feroz que todos punham nessas matérias.

Repare-se que a Casa de Bragança, ao longo do século XVI, em diferentes episódios das mesmas questões, foi obrigada a defender os seus privilégios. $\mathrm{O}$ argumento decisivo era, todavia, sempre $\mathrm{o}$ mesmo: o facto de possuir o mais antigo título de duque fazia com que a Casa estivesse na posse e costume de preceder a todos os senhores do Reino, com a única excepção dos infantes ou dos filhos legítimos dos infantes. Tal não ocorria, no entanto, caso algum desses filhos o fosse por linha bastarda. Esse defeito de sangue era definitivo e inibia todos os direitos de representação da linha paterna, mesmo que houvesse sido legitimado.

Conflitos de precedências e de tratamentos:

1) Duques de Bragança / Duques de Coimbra-Aveiro( ${ }^{(35)}$

a) Reinado de D. Manuel - Questão de precedências entre D.

$\left({ }^{(34)}\right.$ Kristen B. Neuschel, Word of Honor..., p. 18.

(35) A rivalidade entre estas duas Casas atravessou todo o século XVI e ainda a primeira metade do século XVII e não se expressou, apenas, através das querelas de precedências e formas de tratamento que a seguir se inventariam. Citemos apenas dois outros episódios ligados ao controlo imposto pelas ditas linhagens sobre a construção da sua memória e que foram intervalados por quase um século: as referências à Casa de Bragança que Damião de Góis incluiu na sua crónica do príncipe D. João, suscitaram 
Jaime e D. Jorge, Mestre de Santiago e Avis, resolvida a favor do duque Bragança $\left({ }^{36}\right)$.

b) Concessão do título de duque de Barcelos ao herdeiro da Casa de Bragança - carta do duque de Aveiro à rainha reagindo à notícia do requerimento que o duque de Bragança D. Teodósio I fizera de ser concedido o título de duque a seu filho primogénito, expondo as razões para obter igual graça para seu filho, o marquês de Torres Novas "porque naõ he cousa que se posa pasar, fazerse tamta diferença hu de nosos filhos herdeiros ao outro", uma vez que na corte portuguesa havia diferença grande de estatuto entre marqueses e duques $\left({ }^{37}\right)$.

c) 1584 - Concessão do tratamento de Excelência ao duque de Bragança - Foi concedido informalmente ao duque D. João I e depois formalizado com D. Teodósio II (confirmado por alvará de Filipe II em 1605) e, depois, a D. João II $\left({ }^{38}\right)$. Depois de porfiados requerimentos e análise política, o duque de Aveiro acabou por obter esta distinção, em $1606\left({ }^{39}\right)$.

2) D. Constantino e D. Fulgêncio /?

- 1533 - O rei salvaguardou aos dois irmãos do duque de Bragança os direitos de precedência que cada um tinha no paço, não

veemente protestos ao Marquês de Ferreira e a subsequente revisão do texto pelo autor (cf. "Introdução" de Alberto Martins de Carvalho à reedição da Crónica de ElRei D. João II e Mafalda Soares da Cunha, "D. João II e a Construção do Estado Moderno. Mitos e Perspectivas Historiográficas", in Arqueologia do Estado. $1^{a}$ s Jornadas sobre Formas de Organização e Exercício dos Poderes na Europa do Sul, sécs. XIII-XVIII, vol. II, Lisboa, 1988, pp. 649-667; no primeiro terço de seiscentos surgiu uma outra questão dessa vez a propósito da publicação da obra de Agostinho Manuel de Vasconcelos, cf. António Oliveira, "Para a História do Embargo à Publicação da Obra de D. Agostinho Manuel de Vasconcelos, Vida y Acciones del Rey Don Juan el Segundo", O Instituto, vol. CXXXIX, 1979, pp. 17-33.

${ }^{\left({ }^{36}\right)}$ António Caetano de Sousa, HGCRP, t. VI, p. 35.

${ }^{(37}$ ) António Caetano de Sousa, Provas..., t. VI, P. 1a, pp. 43-54. A citação é das pp. 43-44.

(38) BNM, Ms. 1439, fl. 272v; António Caetano de Sousa, Provas..., t. IV, P. $1^{\text {a }}$, p. 359 e HGCRP, t.VI, p. 97.

$\left(^{39}\right)$ António Caetano de Sousa, Provas..., t. IV, P.12 , p. 380. 
obstante terem ocorrido equívocos sobre a matéria no baptizado do infante D. Filipe $\left({ }^{40}\right)$.

3) D. Dinis, irmão do duque de Bragança / D. Afonso, filho natural de D. Diogo, duque ile Visen

- Reinado de D. Manuel - contenda de precedências resolvida a favor de D. Dinis, com base no mesmo argumento da bastardia $\left({ }^{41}\right)$.

4) Duque de Bragança / D. António, prior do Crato

a) 1556-1562 - disputa da precedência em cortes que acabou por ser resolvida favoravelmente ao duque como se comprova pelas precedências estabelecidas nas cortes de 1562 e no auto de levantamento de D. Sebastião $\left({ }^{42}\right)$.

b) 1568 - por, em seguida ao senhor D. Duarte, filho do infante D. Duarte, ter sido dado o tratamento de Excelência ao prior do Crato, antes de o ser ao duque de Bragança $\left({ }^{43}\right)$.

c) 1578 - novo episódio desta vez assente sobre as diferenças de entendimento entre direito de posse de precedências e direito de propriedade das mesmas $\left({ }^{44}\right)$.

Assuntos de tão vital importância justificavam que se reduzissem a escrito os conjuntos de normas e costumes sobre tratamentos. Filipe II foi, porém, mais longe. Procurou inovar, seguindo usos e estilos castelhanos. Assim, foi entregue a D. Teodósio II um papel onde se explicitava o modo como os reis tratavam os duques da Casa, pormenorizando as excepções e as circunstâncias em que podiam, ou não, ser alteradas tais práticas $\left({ }^{45}\right)$. $\mathrm{O}$ duque reagiu. Criticava a mudança insurgindo-se sobretudo contra as preeminências que, na Lei das Cortesias de 1597, Filipe II concedera aos marqueses e filhos de marqueses - até então tinham constituído privilégio exclusivo do título ducal e esta liberal lei viera destruir esses indicadores de distinção - e contra a falta de atenção para com os

(40) António Caetano de Sousa, Provas,.., t. IV, P.1 ${ }^{\mathrm{a}}$, p. 114.

(41) António Caetano de Sousa, HGCRP, t. VI, p. 87.

( $\left.{ }^{42}\right)$ António Caetano de Sousa, Provas..., t. IV, P. 1a, pp. 195-199 e BNL, cx. $7, n^{\circ} 23$.

(43) António Caetano de Sousa, HGCRP, t. VI, pp. 84 e 85-92.

(44) António Caetano de Sousa, Provas..., t. IV, P. $1^{\text {a }}$, pp. 350-351.

(45) António Caetano de Sousa, Provas..., t. IV, P. $1^{\text {a }}$, pp. 286-288. 
usos e costumes particulares da Casa de Bragança. Entendia-se que a dita Lei os deveria mencionar como excepção, face ao que se dispunha para os restantes senhores $\left({ }^{46}\right)$. $O$ duque levou avante na maioria dessas pretensões, uma vez que persistiu no uso das mesmas formas de tratamento e de assinatura que até então adoptara.

O clima de competição generalizada entre os aristocratas, traduzido nestas disputas pelos signos de distinção, revela bem a importância já conferida ao status, à simbólica do poder tomada ela própria como identidade com o próprio poder. Demarcava e distanciava, também, a monarquia que era árbitro e de quem, implicitamente, se iam aceitando os critérios de classificação social.

O que não obsta a que muitos destes grandes aristocratas, incluindo o duque de Bragança, não residissem em permanência na corte. Não obsta, igualmente, a que grande parte deles não fizesse parte do núcleo central e próximo do exercício directo da governação e que se preocupasse ainda de modo determinante com o exercício efectivo do governo dos seus senhorios.

A residência permanente dos duques era em Vila Viçosa. Não como consequência da dominação filipina, como algumas leituras da Corte da Aldeia de Francisco Rodrigues Lobo têm sugerido, mas por decisão política. A estruturação da corte ducal em Vila Viçosa data do regresso do $4^{\circ}$ duque de Castela, ainda em finais do século XV. Os investimentos na construção e no engrandecimento do palácio ao longo de todo este período, a criação e os melhoramentos da tapada e as repercussões da permanência da corte brigantina na reorganização das áreas de crescimento da vila são testemunho cabal do carácter sistemático da presença ducal em Vila Viçosa. A própria centralidade da administração senhorial brigantina corrobora, de resto, esta imagem.

A decisão de construir a residência ducal fora dos constrangimentos espaciais do Castelo oferece um argumento adicional à ideia que aqui vimos defendendo sobre a atenção constante que a Casa de Bragança dedicava à evolução das formas de representação. $O$ paralelismo existente entre a tomada de decisão manuelina de deslocar o Paço Real do Castelo para a Ribeira e a opção brigantina de construir a nova morada na Horta do Reguengo tem já sido sublinhado por

${ }^{(46)}$ António Caetano de Sousa, Provas..., t. IV, P. 1a, pp. 366-373. 
alguns estudiosos $\left({ }^{47}\right)$. A breve trecho, essa mudança espacial revelouse como um projecto coerente de reorganização da própria lógica do tecido urbano calipolense por forma "a exaltar a fama da linhagem, ombreando, senão superando, com a própria casa real" $\left({ }^{48}\right)$.

Assim, a Casa de Bragança, para além dos grandes e concentrados senhorios eclesiásticos como Alcobaça ou Tibães, foi talvez aquela que mais sistematicamente preferiu a distância da corte, a comunicação intermediada, a pressão e a influência através de terceiros. No conjunto deste século e meio, não terá passado mais de meia dúzia a uma dúzia de anos na corte do rei. O período mais longo que conhecemos é de cerca de quatro anos, entre 1533 e 1536, quando o rei sediou em Évora. Quanto ao mais, deslocava-se sempre que algum acontecimento marcante ocorria: baptismos, casamentos e funerais de membros da família real e às cortes. Ou ainda visitas, rápidas e com escassa comitiva, como a que ocorreu em 1542 para saber da saúde do monarca que estava doente, em Lisboa $\left({ }^{49}\right)$.

A opção de não partilhar os mesmos espaços, as mesmas estratégias cortesãs e as mesmas sociabilidades da restante nobreza constituia, assim, um outro elemento de afirmação da alteridade da Casa de Bragança. A distância, atributo do poder, era mais um recurso simbólico ao serviço da sua preeminência.

Malgrado esta distância física da corte régia, os duques mantiveram algum nível de intervenção política no centro $\left({ }^{50}\right)$ e, sobretudo,

(47) José Teixeira, O Paço Ducal de Vila Viçosa. Sua Arquitectura e suas Coleç̧ōes, Lisboa, Fundação da Casa de Bragança, 1983, p. 14 ss..

(*) Rafael Moreira, "Uma 'Cidade Ideal' em Mármore. Vila Viçosa, a Primeira Corte Ducal do Renascimento Português", Monumentos, $\mathrm{n}^{\circ}$ 6, 1997 , pp. 48-53 (cit. p. 50) e Luiz Sá Pereira, "Nota Histórico-Interpretativa de Transformações Urbanísticas em Vila Viçosa", Monumentos, n 6, 1997, pp. 54.57 .

(49) António Caetano de Sousa, HGCRP, t. VI, p. 23.

(50) Entre 1528 e 1532, o embaixador castelhano em Portugal, Lope Hurtado de Mendonza, afirmou reiteradamente a importância política do duque de Bragança na construção dos processos de decisão política da monarquia. É verdade que detinha a sua principal conexão na rainha $D$. Catarina e no próprio infante D. Luís, cf. Aude Viaud, "La Cour de Portugal vue par Lope Hurtado de Mendoza (1528-1532)", in La Découverte, Le Portugal et l'Europe, Actes du Colloque, Paris, les 26, 27 et 28 mai 1988, Paris, Fundação Calouste Gulbenkian, Centro Cultural Português, 1990, pp. 131-140. Percebese, por isso, que a emergência das novas formas de organização pessoalizada 
uma indiscutivel capacidade de consolidarem e reproduzirem a preeminência da sua posição social. O seu poder, repita-se, não decorria simplesmente do status. Exercia-se sobre um espaço que alguns diziam (exageradamente, embora) corresponder a um terço do reino, que incluía alguns bem populosos concelhos (estimava-se que tivesse mais de 200000 vassalos( $\left.{ }^{51}\right)$ ) e uma imensidão de recursos de toda a ordem $\left({ }^{52}\right)$. E, como se sugeriu, a atenção concedida à preservação dos seus privilégios era contínua. Uma das provas possíveis pode ser apresentada na alteração do perfil político e social dos agentes do duque de Bragança em Madrid, após a tomada de poder do condeduque de Olivares. O recrutamento dos agentes da Casa na corte madrilena passou a ser socialmente mais selectivo, beneficiaram depois de mercês mais importantes que os seus antecessores, chegando mesmo a serem agraciados com as maiores distinções proporcionadas pelos Bragança - comendas, nomeadamente - o que até essa data se não verificara, porque ao cargo não era atribuído igual importância estratégica.

Nestas épocas, o poder senhorial resultava ainda de uma profunda imbricação entre status e efectivos poderes de governo. Segundo estudos recentes, a evolução histórica ditaria o fim deste modelo de poder senhorial $\left({ }^{53}\right)$. A partir de finais do século XVII, a presença na corte e os serviços directos à monarquia passariam a constituir os elementos determinantes do poder social da grande

das tomadas de decisão, com a figura dos secretários e dos validos de D. João III, correspondeu a uma perda de influência da Casa. Relativa, todavia. E novamente recuperada no momento da regência dessa rainha, cf. Maria do Rosário Azevedo Cruz, As Regências na Menoridade de D. Sebastião..., vol. I. Mesmo após 1580, parece que os monarcas austríacos lidavam cautelosa e atentamente com a Casa. Dizia-se, a propósito da promoção do bispo de Elvas a arcebispo de Braga que fora resultado da intervenção do duque em Madrid, para agraciar as mercês que este lhe tinha feito aquando do recebimento em Elvas de D. Luísa de Gusmão, pois "uma carta do Serenissimo Senhor valia e podia muito na Corte de Madrid e quanto queria lhe concedia aquele Católico Rei", António Cadornega, Descriçāo de Vila Viçosa ..., p. 70.

(51) Valor apresentado pelo embaixador veneziano Leonardo Moro, apud António Oliveira, Poder e Oposição Política em Portugal no Período Filipino (15801640), Lisboa, Difel, 1991, p. 48, nota 5.

(52) Mafalda Soares da Cunha, As Redes Clientelares da Casa de Bragança..., cap. II, ponto 3 .

${ }^{(53)}$ Nuno Gonçalo Monteiro, A Casa e o Património dos Grandes Portugueses 
mobreza do Reino. Lógica que nestas épocas podia ainda ser secundária como se comprova pelo caso concreto da Casa de Bragança.

\section{Privilegios comerciais}

O monopólio que a Coroa impusera, pelo menos no plano dos princípios, sobre o comércio com as Índias Orientais proporcionouThe um leque de extraordinários recursos financeiros sobre o qual assentava o equilíbrio das finanças régias $\left({ }^{54}\right)$. Mas, igualmente importantes foram as repercussões sociais decorrentes da ocupação e controlo militar desse espaço comercial. As oportunidades de serviço que geraram em diferentes escalões da sociedade suscitaram um surto de mobilidade social e, em particular, uma grande abertura das fronteiras inferiores do grupo nobiliárquico. Também, sob esta dupla vertente, a Casa de Bragança procurou obter a sua parte nestes novos recursos da monarquia.

James C. Boyajian destacou recentemente a importância económica dos privilégios que os Bragança detinham sobre o comércio das especiarias orientais - obtidos logo no início da centúria de quinhentos e sempre renovados pelos sucessivos monarcas $\left({ }^{55}\right)$ sugerindo ainda que a concretização desses direitos teria suscitado algum envolvimento com as redes de mercadores que tratavam no Oriente $\left({ }^{56}\right)$. O negócio efectivava-se ou sob a forma de transferência

(1750-1832), Lisboa, F.C.S.H - U.N.L., 1995 (dissert. de doutoramento, mimeo.). Este trabalho constitui, de resto, o melhor contraponto ao estudo que aqui se realiza sobre a Casa de Bragança. Quase tudo o que esta era e detinha desaparece das lógicas de afirmação social dos grandes aristocratas de finais de Antigo Regime.

${ }^{(54)}$ Cf. Vitorino Magalhães Godinho, "Finanças Públicas e Estrutura do Estado", in Dicionário de História de Portugal, $2^{a}$ ed., Lisboa, Iniciativas Editoriais, vol. III , pp. 20-40 e a síntese de Joaquim Romero Magalhães, "A Fazenda", in História de Portugal, dir. José Mattoso, vol. III, O Alvorecer da Modernidade (1480-1620), coord. J. Romero Magalhães, Lisboa, Círculo de Leitores, 1993, pp. 90-105.

${ }^{\left({ }^{5}\right)}$ Cf. Mafalda Soares da Cunha, As Redes Clientelares da Casa de Bragança..., cap. I, 2.1.3, especialmente, nota 190 e cap. II, ponto 3, 1.3., sobretudo na nota 186.

${ }^{(56)}$ James C. Boyajian, Portuguese Trade in Asia under the Habsburgs, 15801640, Baltimore-Londres, Johns Hopkins University Press, 1992, pp. 34 e 4345. 
de direitos de representação - através da nomeação de agentes seus em Goa e Cochim - ou sob a forma de venda desses mesmos direitos a mercadores aí estabelecidos. Embora implicasse um investimento prévio de capital - o privilégio era constituído pelo direito de compra de uma determinada porção de especiarias, com isenção de impostos à Coroa - , o certo é que os provento daí retirados atingiam quantias muito significativas. Ainda segundo o mesmo autor, os agentes do duque de Bragança em Goa e Cochim teriam despachado, entre 1584 e 1602, 6009 quintais de canela avaliados em mais de 500000 cruzados $\left({ }^{57}\right)$ (ou seja, mais de 200 contos de réis, o que representaria uma média anual de cerca de 11 contos de réis). Neste estudo, não importa muito saber se e como a Casa teria rentabilizado este direito $\left({ }^{58}\right)$, mas apenas destacar o facto de o possuir e de o ter sempre conseguido renovar.

Acrescente-se, ainda, que a primeira lista das contrapartidas feita em 1580 também incluía pretensões sobre esta matéria. Sugeriase, antes de mais, que os privilégios de importação de especiarias do Oriente perdessem o estatuto precário da concessão em vidas e se tornassem perpétuos. Solicitava-se, depois, que o duque pudesse "para sempre prover em cada hu año a Capitania de hua das naos de viagem para a India: e que as pessoas que elles assi proverem, aião per conta da fazenda de V. M.de e de seus soccessores todos os ordenados dos Capitães das ditas naos e todos os proes e percalços, que the pertencem" $\left({ }^{59}\right)$.

Quanto às oportunidades de serviço é verdade que tiveram um impacto menos expressivo entre as clientelas brigantinas. $\mathrm{Ou}$ melhor, as oportunidades de serviço no Império Oriental não parecem ter sido um vector central na estruturação das redes brigantinas. Deve-se no entanto sublinhar a protecção ducal dispensada ao governador Lopo Vaz de Sampaio depois da sua queda em desgraça $\left({ }^{60}\right)$ e o facto de D. Constantino, irmão de D. Teodósio I, ter

(57) James C. Boyajian, Portuguese Trade in Asia..., p. 45.

$\left.{ }^{58}\right)$ Segundo alguns cronistas brigantinos, parece que não. $O$ duque $D$. Teodósio II teria mesmo argumentado a um reparo sobre o desperdício de ter tão grandes quantidades de canela armazenadas em Lisboa que estavam guardadas para arderem no casamento de seu filho.

$\left.{ }^{(59}\right)$ Queirós Velloso, O Interregno dos Governadores..., p. 250.

$\left({ }^{60}\right)$ Não importam aqui as razões concretas subjacentes a esta queda em desgraça, mas apenas referir que ela surgiu após uma feroz luta entre o que 
sido chamado pelo monarca - por sugestão directa do próprio duque - a desempenhar o cargo de vice-rei da Índia em 1558. A sua comitiva integrou um grande número de criadagem brigantina, que desses serviços retirou oportunidades de alargamento das respectivas redes de aliança e mercês complementares da monarquia. Alguns dos grandes criados brigantinos desempenharam, ao longo dos tempos, funções de capitania de naus ou de praças militares na Índia( $\left.{ }^{61}\right)$ e parte dos principais grupos linhagísticos presentes no Oriente ao

alguns interpretam como tendo sido duas concepções administrativas do império oriental opostas a que se associava um confronto entre duas redes de interesses indianos e respectivas facções na corte régia. O duque de Bragança protegia a facção que Lopo Vaz de Sampaio encabeçara, mas que à laz dos pareceres jurídicos suscitava fortes dúvidas. As motivações subjacentes a esse patrocínio ducal não são claras. $O$ vínculo à Casa de Bragança decorria do facto do governador agrilhoado ser genro de D. João de Eça, alcaide mor de Vila Viçosa e um dos criados de maior valia do duque D. Jaime. Desconhecemos se mais interesses estavam em jogo, mas o certo é que provocou o empenhamento ducal traduzido em alguma correspondência entre o duque e o monarca, no sentido de melhorar a situação do exgovernador. Cf. carta do duque de 1530 em que este dizia "antre minhas mofinas comto eu esqueçer se V.A. da merce que me tinha feita de nom usar de nenhuu Rigor contra lopo vaaz de Sampayo sem primeiro ho ouuir...", ANTT, Corpo Cronológico, P. $1^{\text {a }}$, março 45, doc. 103.

(*) Muitas dessas referências encontram-se em Registo da Casa da India, cum introdução, índices e notas de Luciano Ribeiro, 2 vols., Lisboa, Agência Ceral do Ultramar, 1954-55. Refiram-se, a título de exemplo apenas alguns nomes de entre os principais criados brigantinos. Os Caminha eram um dos grupos familiares mais atentos à exploração desses recursos. Para além de floấo de Tovar Caminha que militou na India em 1567 onde herdara do pai ou do sogro (as fontes variam) a alcaidaria mor de Mangalor e em 1588 xcltou ao Oriente como capitão mor de uma armada (António Caetano de Secusa, HGCRP, t. II, P. $2^{\text {a }}$, 66 e t. VI, p. 653) e de Pedro de Andrade Caminha, ver, ainda, o caso de Francisco Caminha que em 1519 recebeu a capitania da naws Santo António e por isso ia à Índia (Registo da Casa da Índia, vol. I, p. 11). Oulras situaçōes podem igualmente ser detectadas entre os descendentes do ande de Faro que serviam D. Teodósio II e entre os Vaz Pinto. D. Afonso de Nistcunha foi, em 1608, como almirante da armada em que era capitão-mor o cunde da Feira e, em 1618, voltou ao Oriente, já como capitão-mor da armada (Antiónio Caetano de Sousa, HGCRP, t. IX, p. 145); António de Ataíde Pinto permaneceu mais de quinze anos no Oriente onde militou nos mares de Slalace como capitão mor das armadas, pelo que foi agraciado com a capitania 
longo do século XVI e da primeira metade do século XVII eram directamente conotados como pertencendo à órbita de influência dos duques de Bragança $\left({ }^{62}\right)$.

Este sumário apontamento à atenção brigantina em participar dos recursos simbólicos e materiais que a Coroa ia criando não pretende, de forma alguma, esgotar os indicadores possíveis de serem apresentados. Parece-nos, no entanto, suficiente para demonstrar que a Casa de Bragança não só conhecia a importância dos códigos de representação enquanto meio de afirmação política, como os articulava sistematicamente com os instrumentos e os mecanismos concretos de intervenção política. Quer isto dizer que - e ao contrário do que ocorreria com a grande maioria dos titulares em finais do Antigo Regime - os Bragança tinham quer a clara percepção do valor da utilização conjugada desse tipo de recursos, quer o poder político necessário para os solicitar e, em muitos casos, obter. E, mesmo quando as suas expectativas foram defraudadas, como em grande medida ocorreu com a negociação de contrapartidas pela renúncia do trono em 1580, é importante sublinhar que só o facto de esses desejos serem verbalizados denota a própria plausibilidade de os adquirir. Seria impensável exprimir e, neste caso, negociar a impossibilidade.

A existência de uma casa senhorial dotada de tal amplitude de poder ao longo do século XVI e da primeira metade do século XVII pode ainda apresentar algumas virtualidades para clarificar a própria lógica e as estratégias de organização dos poderes em Portugal, no

de Baçaim (F. Morais Sardinha, Parnaso de Vila Viçosa..., fls. 113-115). Apontese, por fim, o caso de Nicolau da Veiga (outro comendador da Casa) que recebera por carta patente de 23 de Março de 1585 o direito a servir os ofícios de feitor, alcaide mor e vedor das obras da fortaleza de Moçambique na vagante dos providos antes de Janeiro desse ano de 1585, o que só se veio a verificar em 1644 (ANTT, Chancelaria de D. João IV, L. 17, fls. 21v e 22).

$\left({ }^{62}\right)$ Era o caso dos Gama, dos Pereira e dos Castro, por exemplo. E também de alguns Sousa, principalmente os que pertenciam ao grupo linhagístico do governador Martim Afonso de Sousa (anteriormente criado da Casa de Bragança), uma vez que foram objecto do seu generoso patrocínio. Cf. Sanjay Subramanyam, O Império Asiático Português, 1500-1700. Uma História Política e Económica, Lisboa, Difel, 1995 (ed. original de 1993), pp. 125-136. 
início da época moderna, sobretudo se as compararmos com as de outras regiões da Europa Ocidental. Ou seja, parece difícil encontrar, na primeira metade do século XVII, uma outra casa senhorial que participasse de forma tão próxima dos signos e das estruturas de poder da monarquia. 